\title{
Characteristics of reduced-fat muffins and cookies with native and modified rice starches
}

\author{
Young-Tack Lee*, Pradeep Puligundla \\ Department of Food Science and Biotechnology, Gachon University, Seongnam, Gyeonggi 13120, Korea
}

\section{A B S T R A C T}

\begin{abstract}
In the present study, native and chemically modified (acetylated and hydroxypropylated) rice starches were partly substituted for butter in the production of reduced-fat muffins and for shortening in cookies. Physicochemical characteristics of native and modified rice starches were investigated. All the three types of starches were substituted at $20 \%$ level in muffins and cookies. The crude protein content of modified rice starches was significantly low compared to native starch. A slight variation was observed in the color characteristics of native starch upon modification. However, there were no significant differences $(p>0.05)$ in physical (volume, weight, density, height, color of crust and crumb) as well as sensory (appearance, grain, flavor, texture and overall acceptability) properties between baked reduced-fat muffins and full-fat ones. Similar results were obtained with reduced-fat sugar-snap cookies, in which shortening fat was partly substituted by rice starches. In conclusion, both native and modified rice starches are equally well suited for partial substitution of fat in regular muffins and cookies.
\end{abstract}

Keywords: Rice starch; Chemical modification; Reduced-fat muffin; Cookie; Sensory properties

\section{INTRODUCTION}

The consumer preference for reduced fat/calorie foods has increased in recent years as obesity-related health risks are escalating at an alarming rate. However, issues such as long-term acceptance of these foods, poor organoleptic properties and doubts over their overall nutritional value are limiting the popularity of reduced-fat foods. Especially, the organoleptic properties of many reduced fat/calorie foods are presumed to differ from their full-fat counterparts. In short-term organoleptic tests, they have been evaluated as inferior to full-fat ones (Sandrou and Arvanitoyannis, 2000). There is no single fat replacer that contributes all of the functional and sensory qualities of fat to all reduced-fat products (Roller, 1996). Studies show that starch-based fat replacers, including modified starches, can impart finished products with organoleptic characteristics similar to their full-fat counterparts. The use of starches, native and modified, as fillers in reduced-fat food formulations, has been suggested for a long time (Lobato-Calleros et al., 2014).

Generally, native or unmodified starches find limited applications in food systems due to their instability under various temperature, $\mathrm{pH}$, and shear conditions. Starch is relatively inert in its native form; and, therefore, needs modification to achieve more desirable functional properties (Bao and Bergman, 2001). The modification can be done by chemical, physical or genetic methods. Chemical modification is the major route for the production of modified starch (Abbas et al., 2010). Chemical modification of starch is generally carried out through the introduction of functional groups into the starch chains by chemical means. Such introduced groups change the properties of starches and extend their applications in food systems. The ultimate goal of many chemical modifications to starch is to alter its cooking characteristics, increase paste viscosity, decrease retrogradation and paste and/or gel syneresis, increase freeze-thaw stability, and improve adhesion as well as emulsion stability (Bao and Bergman, 2001; Chun and Yoo, 2007).

Acetylated starch is prepared by reaction of starch with acetic anhydride under aqueous conditions in the presence of dilute sodium hydroxide. Acetylation of rice starch increases its swelling power, solubility, viscosity and the adhesiveness, firmness and cohesiveness of gels (Jae et al., 1994); lower initial pasting temperature and

\footnotetext{
${ }^{*}$ Corresponding author:

Prof. Young-Tack Lee, Department of Food Science and Biotechnology, Gachon University, Seongnam, Gyeonggi 13120, Korea.

Tel: +82-31-750-5565, Fax: +82-31-750-5273, E-mail: ytlee@gachon.ac.kr
}

Accepted: 05 March 2016;

Published Online: 15 March 2016 
setback (Gonzalez and Perez, 2002). Therefore, acetylated starch is used as thickening agent for food applications (Mirmoghtadaie et al., 2009). Compared with native starch, the extent of physicochemical property changes in an acetylated starch is dictated by the degree of acetylation or degree of $\mathrm{C}=\mathrm{O}$ substitution (Phillips et al., 1999). The properties of acetylated starch also depend on the amylose/ amylopectin ratio, the botanical source of starch, etc. (Bello-Perez et al., 2010).

The hydroxypropylated starches can be prepared by etherification of native starch, in the presence of an alkaline catalyst, with propylene oxide (Chun and Yoo, 2007). As hydroxypropyl groups are hydrophilic, they disrupt or weaken the internal bond structure when introduced into starch chains, and thus alter physicochemical properties (Yeh and Yeh, 1993; Liu et al., 1999; Xie et al., 2005). There have been numerous studies on the physicochemical properties of various dispersions of hydroxypropylated starches, such as corn (Liu et al., 1999; Han et al., 2005), potato (Kaur et al., 2004), and wheat (Choi and Kerr, 2004; Hung and Morita, 2005).

Rice starch has outstanding properties for use as a fat substitute (Yi et al., 2012). Fat replacement in sausage formulations with phosphorylated and extruded broken rice starch was shown to yield low-calorie products with acceptable sensory characteristics (Limberger et al., 2011). Rice starches can be chosen in order to provide a creamy texture to foods as the granules of rice starch are nearly the same size as fat globules (Lee et al., 2013). This study was conducted to further explore its potential use as the fat replacer. Initially, the physicochemical characteristics of rice starch (native) and its modified forms, acetylated and hydroxypropylated rice starches, were determined. These starches were applied in the formulation of reduced-fat muffins and cookies as fat mimetics. Therefore, another aim of this study was to evaluate the sensory (organoleptic) characteristics of baked reduced-fat muffins and cookies containing rice starches.

\section{MATERIALS AND METHODS}

\section{Materials}

Wet-milled rice flour for starch isolation was obtained from Pan-Pacific Co., Ltd. (Ansan, Korea). Commercial cookie flour was obtained from Daehan Flour Mills Co., Ltd. (Inchon, Korea).

\section{Starch isolation}

Rice starch was separated from rice flour according to an alkaline steeping method of Yamamoto et al. (1973). The rice flour was blended in the presence of $0.2 \% \mathrm{NaOH}$
$(1: 5, \mathrm{w} / \mathrm{v})$ for 2 min using a Waring blender (HGB 25E1, Waring products Inc., Torrington, CT, USA). The slurry was then passed through 100 and 200 mesh sieves. The filtrate was centrifuged at $4,800 \times \mathrm{g}$ for $10 \mathrm{~min}$, the supernatant was discarded, and the remaining starch residue was extracted again with $0.2 \% \mathrm{NaOH}$. The sedimented starch was washed with distilled water three times and dried at room temperature for 2 days.

\section{Starch modification}

Acetylated rice starch was prepared by reacting native rice starch with $8 \%$ acetic anhydride according to the method described by Wurzburg (1964). Hydroxypropylated rice starch was prepared using $8 \%$ propylene oxide according to the method of Wootton and Manatsathit (1984) with slight modification.

\section{Physicochemical characteristics of rice starches}

The crude protein and ash contents were determined by AACC methods 46-11A and 08-01, respectively (AACC, 2000). Crude fat content was determined using AOAC Soxhlet method (AOAC, 2000). Particle size distributions of rice starch were determined using a particle size analyzer (CILAS model 1064L, France). The average particle size was calculated using the software provided by CILAS and was expressed in $\mu \mathrm{m}$. Color of rice starch was measured using a Minolta Chroma Meter (Model CR-300, Minolta Co., Ltd, Osaka, Japan).

\section{Pasting properties}

The pasting properties of the starch samples were evaluated using a Rapid Visco Analyzer (Newport Scientific, Warriewood, Australia). Rice starch (3 g, 14\% mb) was transferred into an aluminum RVA canister and $25 \mathrm{~mL}$ of distilled water was then added. The sample was maintained at $50{ }^{\circ} \mathrm{C}$ for $1 \mathrm{~min}$, heated to $95^{\circ} \mathrm{C}$ in $7.5 \mathrm{~min}$, and held at $95^{\circ} \mathrm{C}$ for $2.5 \mathrm{~min}$. The sample was cooled to $50{ }^{\circ} \mathrm{C}$ in $7.5 \mathrm{~min}$, and then maintained at $50{ }^{\circ} \mathrm{C}$ for $2.5 \mathrm{~min}$. The rotating speed of paddle was maintained at $960 \mathrm{rpm}$ for $10 \mathrm{~s}$, and then at $160 \mathrm{rpm}$ during the heating and cooling cycles. The viscosity was expressed as rapid viscosity units (RVU). The parameters recorded include pasting temperature, peak viscosity, hot paste viscosity or trough (minimum viscosity at $95^{\circ} \mathrm{C}$ ), breakdown viscosity (peaktrough), cool paste viscosity or final viscosity (at $50{ }^{\circ} \mathrm{C}$ ), and setback (final-peak).

\section{Preparation of muffin}

The experimental muffin formula is shown in Table 1. Butter, sugar and eggs were mixed using a Hobart N50 mixer for 1 min at speed 1 (low speed) and $1 \mathrm{~min}$ at speed 2 (medium speed). The sifted dry ingredients were added and blended at speed 1 for $30 \mathrm{~s}$. Water was added and mixed at speed 1 for $30 \mathrm{~s}$ and speed 2 for $30 \mathrm{~s}$. Batter samples 
(75 g) were weighed into each muffin cup of an aluminum pan and baked in a reel oven (National Mfg. Co., Lincoln, $\mathrm{NE}, \mathrm{USA}$ ) at $204^{\circ} \mathrm{C}$ for $24 \mathrm{~min}$.

Sugar-snap cookies were prepared according to AACC method 10-52 (AACC, 2000). Shortening (fat) was substituted by rice starch in the range $0-30 \%$. The formula for making sugar-snap cookie is shown in Table 1. Cookie dough was prepared using a micro-mixer (National Mfg., Lincoln, NE, USA) with head speed of $172 \mathrm{rpm}$ and special cookie dough bowl. The dough was rolled to a thickness of $7 \mathrm{~mm}$ and cut with a cookie cutter (60 mm ID). Cookies were immediately baked for $11 \mathrm{~min}$ at $205^{\circ} \mathrm{C}\left(400{ }^{\circ} \mathrm{F}\right)$ in a reel oven (National Mfg., Lincoln, NE, USA), cooled $5 \mathrm{~min}$, and then removed from baking sheet. They were further cooled to room temperature and stored in plastic bags until used.

\section{Physical evaluation}

The diameter and thickness of cookies were measured using two cookie samples which had been completely cooled to room temperature, and cookie spread was calculated as the mean diameter of two cookies from single dough. Spread ratio, the ratio of the cookie diameter to the thickness $(\mathrm{D} / \mathrm{T})$, was calculated according to AACC method 10-50D (AACC, 2000). The muffin and cookie volumes were determined by rapeseed displacement method (AACC, 2000), specific gravity (g/cc) was calculated as the ratio of weight to volume. Muffin color was determined using a color difference meter (Minolta CR-400, Osaka, Japan).

\section{Sensory evaluation}

Sensory evaluation was conducted by a 10 -member panel trained from the Department of Food Science and Biotechnology at the Gachon University. Cookies were evaluated using the 9-point hedonic scale, with 9

Table 1: Baking formula for muffin and sugar-snap cookie based on total flour weight (\%, flour basis)

\begin{tabular}{lcc}
\hline Ingredients & Muffin & Cookie \\
\hline Flour & 100.0 & 100.0 \\
Sugar & 60.0 & 60.0 \\
Shortening & - & 30.0 \\
Butter & 40.0 & - \\
Whole egg & 32.0 & - \\
Non-fat dry milk & 7.4 & 3.0 \\
Sodium bicarbonate $\left(\mathrm{NaHCO}_{3}\right)$ & - & 1.00 \\
Sodium bicarbonate $\left(\right.$ in solution $\left.\mathrm{A}^{1)}\right)$ & - & 0.80 \\
Ammonium chloride $\left(\mathrm{NH}_{4} \mathrm{Cl}\right)\left(\right.$ in solution $\left.\mathrm{B}^{2)}\right)$ & - & 0.50 \\
NaCl & 0.4 & - \\
NaCl (in solution $\mathrm{B})$ & - & 0.45 \\
Baking powder & 3.5 & - \\
Water (distilled) & Variable & Variable \\
\hline
\end{tabular}

1)Prepared by dissolving $79.8 \mathrm{~g} \mathrm{NaHCO}_{3}$ in $1 \mathrm{~L}$ of distilled water. ${ }^{2}$ Prepared by dissolving $101.6 \mathrm{~g} \mathrm{NH}_{4} \mathrm{Cl}+88.9 \mathrm{~g} \mathrm{NaCl}$ in $1 \mathrm{~L}$ of distilled water representing the highest degree of liking and 1 the least degree of liking, for the properties including top grain, color, flavor, texture, and overall acceptability. Sensory characteristics for muffin included appearance, grain, flavor, texture and overall acceptability.

\section{Statistical analysis}

All the tests were performed in triplicate, and results were expressed as mean \pm standard deviation. A one-way analysis of variance (ANOVA) and Duncan's multiple range tests were used to establish the statistical significance of differences. Data were analyzed using the SAS version 9.2 software program (SAS Institute, Cary, NC, USA).

\section{RESULTS AND DISCUSSION}

\section{Physicochemical characteristic of native and modified rice starches}

The results of physicochemical analysis of native and modified rice starches are shown in Table 2. Crude protein content of native starch was substantially reduced upon acetylation as well as hydroxypropylation; more than $50 \%$ reduction was noted. Around 25\% decrease and a 12.5\% increase of crude fat were observed in acetylated and hydroxypropylated starches, respectively, compared to native rice starch. On the other hand, 1.66-fold and 3-fold increase of ash content were noted upon acetylation and hydroxypropylation, respectively.

Regarding color values, brightness (L) of native starch decreased slightly, but significantly, upon modification. However, redness (a) and yellowness (b) of native starch were decreased significantly upon hydroxypropylation, but not on acetylation. The size of starch granules was decreased considerably upon modification; about $7.8 \%$ and $34.6 \%$ reductions were observed on acetylation and hydroxypropylation, respectively.

\begin{tabular}{|c|c|c|c|}
\hline & Rice starch & $\begin{array}{c}\text { Acetylated } \\
\text { RS }\end{array}$ & $\begin{array}{c}\text { Hydroxypropylated } \\
\text { RS }\end{array}$ \\
\hline \multicolumn{4}{|l|}{$\begin{array}{l}\text { Proximate } \\
\text { composition }\end{array}$} \\
\hline Crude protein ${ }^{1)}$ & $0.31 \pm 0.13^{\mathrm{a} 2)}$ & $0.16 \pm 0.01^{b}$ & $0.09 \pm 0.05^{b}$ \\
\hline Crude fat & $0.64 \pm 0.06^{a}$ & $0.48 \pm 0.13^{b}$ & $0.72 \pm 0.24^{a}$ \\
\hline Ash & $0.12 \pm 0.00^{c}$ & $0.20 \pm 0.01^{b}$ & $0.37 \pm 0.01^{\mathrm{a}}$ \\
\hline \multicolumn{4}{|l|}{ Color values } \\
\hline$L$ & $95.67 \pm 0.01^{a}$ & $94.98 \pm 0.03^{c}$ & $95.21 \pm 0.09^{b}$ \\
\hline a & $0.14 \pm 0.03^{\mathrm{a}}$ & $0.15 \pm 0.01^{\mathrm{a}}$ & $0.09 \pm 0.01^{\mathrm{b}}$ \\
\hline$b$ & $1.11 \pm 0.01^{a}$ & $1.04 \pm 0.00^{\mathrm{a}}$ & $0.89 \pm 0.03^{b}$ \\
\hline $\begin{array}{l}\text { Mean granule } \\
\text { size }(\mu \mathrm{m})\end{array}$ & $6.41 \pm 0.07^{a}$ & $5.91 \pm 0.01^{b}$ & $4.76 \pm 0.04^{c}$ \\
\hline
\end{tabular}

1)\% $\mathrm{N} \times 5.95$, 2)a-b Different letters in the same row indicate significant differences between the samples $(p<0.05)$ 
RVA viscosity profiles of native and modified rice starches are shown in Table 3. Initial pasting temperatures of acetylated and hydroxypropylated rice starches were significantly $(p<0.05)$ lower than native rice starch pasting temperature. A decreased pasting temperature of rice starch upon modification (acetylation) was reported earlier (Sodhi and Singh, 2005; Colussi et al., 2014). This is one of the many advantages achieved with acetylation. Lower peak viscosities were for modified starches compared to the viscosity of unmodified starch. The observed peak viscosities were in the range of 264-317 RVU, lowest for hydroxypropylated rice starch and highest for native rice starch. On the contrary, a higher (significant at $\mathrm{p}<0.05)$ trough viscosity was exhibited by acetylated rice starch compared to the other two starches. Breakdown viscosity of native starch was decreased upon chemical modifications. Compared to native starch, about $16.8 \%$ and $22.7 \%$ lower breakdown viscosities, while about $46 \%$ and $50 \%$ higher setback viscosities were observed in acetylated and hydroxypropylated rice starches, respectively. Setback viscosity indicates retrogradation index of starch paste. The lowest final viscosity was observed for native starch and the highest was for acetylated rice starch. Viscosity profile of an acetylated starch is profoundly influenced by its amylose content and acetylation reaction temperature and reaction time (Colussi et al., 2014).

\section{Physical and sensory properties of muffin}

Initially, native rice starch was substituted at different levels within the range of $0-50 \%$ (data not shown); however, substitution at the level of $20 \%$ was found optimal for reduced-fat muffin formulations. Compared to full-fat muffins, physical characteristics of reduced-fat muffins were not significantly different $(\mathrm{p}>0.05)$ (Table 4$)$. The volume of muffins having hydroxypropylated starch was relatively lower than the others. Muffins weight was slightly increased on starch addition. Heights of muffins having modified starches were relatively low. The brightness of muffin's crust and the crumb was slightly increased upon starch substitution. All these variations are statistically insignificant at the 0.05 level. Therefore, it can be concluded that neither native nor modified starch addition had negatively affected the overall physical properties of reduced-fat muffins.

In reduced-fat muffins, starch substitution slightly decreases the height of the final baked muffins, compared to full-fat muffins. A similar effect with compact crumb matrix was observed with the increased resistant starch (RS) addition to muffin formulations as shortening replacer (Lin et al., 1994). In baked foods, shortenings play a crucial role by imparting moister mouthfeel, contribute structure, lubricate, incorporate air, and transfer heat (Stauffer, 2005).

As shown in Table 5 , sensory characteristics of reducedfat muffins were not significantly ( $p>0.05)$ different from full-fat muffins (control). Parameters including appearance, grain, texture and overall acceptability of reduced-fat muffins were merely similar to control muffins, except for flavor. A significant reduction (at $\mathrm{p}<0.05$ ) was observed in the flavor of muffin that contains native rice starch, compared to control. However, muffins prepared with the modified starches showed better flavor characteristics compared to native starch added ones.

\section{Physical and sensory properties of cookies}

As shown in Table 6, the diameter of baked, reduced-fat cookies was not significantly different from full-fat cookies.

Table 3: Comparison of rapid visco analyzer (RVA) pasting properties of native and modified (acetylated and hydroxypropylated) rice starches

\begin{tabular}{lcccccc} 
& Initial pasting & \multicolumn{3}{c}{ Viscosity (RVU) } \\
\cline { 3 - 6 } & temp. $\left({ }^{\circ} \mathbf{C}\right)$ & Peak & Trough & Breakdown & Final & Setback \\
\hline Rice starch & $70.69 \pm 0.48^{\mathrm{a}}$ & $317.19 \pm 2.46^{\mathrm{a}}$ & $80.15 \pm 1.18^{\mathrm{b}}$ & $\left.237.04 \pm 2.98^{\mathrm{a} 2}\right)$ & $192.50 \pm 4.93^{\mathrm{b}}$ & $-124.69 \pm 6.45^{\mathrm{b}}$ \\
Acetylated RS & $64.72 \pm 0.62^{\mathrm{b}}$ & $300.42 \pm 4.45^{\mathrm{b}}$ & $103.21 \pm 1.43^{\mathrm{a}}$ & $197.21 \pm 3.16^{\mathrm{b}}$ & $233.38 \pm 6.58^{\mathrm{a}}$ & $-67.04 \pm 5.11^{\mathrm{a}}$ \\
Hydroxypropylated RS & $64.66 \pm 0.40^{\mathrm{b}}$ & $264.12 \pm 1.39^{\mathrm{c}}$ & $80.94 \pm 1.39^{\mathrm{b}}$ & $183.19 \pm 2.90^{\mathrm{c}}$ & $201.67 \pm 2.96^{\mathrm{b}}$ & $-62.46 \pm 2.99^{\mathrm{a}}$ \\
\hline
\end{tabular}

1)Trough=Minimum viscosity after the peak viscosity, breakdown=Peak viscosity minus trough viscosity, setback=Final viscosity minus peak viscosity, ${ }^{2 a-c}$ Different letters in the same column indicate significant differences between the samples $(p<0.05)$

Table 4: Effect of fat (butter) replacement (at 20\% level) in muffin formulations with native and modified (acetylated and hydroxypropylated) rice starches on the physical characteristics of corresponding baked muffins ${ }^{1)}$

\begin{tabular}{lcccc} 
& Control & Rice starch & Acetylated RS & Hydroxypropylated RS \\
\hline Volume (cc) & $166.65 \pm 9.40^{\mathrm{a} 2)}$ & $169.20 \pm 3.54^{\mathrm{a}}$ & $170.00 \pm 0.78^{\mathrm{a}}$ & $158.30 \pm 7.07^{\mathrm{a}}$ \\
Weight (g) & $62.50 \pm 0.57^{\mathrm{a}}$ & $62.90 \pm 0.42^{\mathrm{a}}$ & $63.00 \pm 0.28^{\mathrm{a}}$ & $63.50 \pm 0.57^{\mathrm{a}}$ \\
Density (g/cc) & $0.38 \pm 0.03^{\mathrm{a}}$ & $0.37 \pm 0.02^{\mathrm{a}}$ & $0.39 \pm 0.01^{\mathrm{a}}$ & $0.40 \pm 0.00^{\mathrm{a}}$ \\
Height (cm) & $6.10 \pm 0.14^{\mathrm{a}}$ & $6.25 \pm 0.07^{\mathrm{a}}$ & $5.70 \pm 0.42^{\mathrm{a}}$ & $5.74 \pm 0.47^{\mathrm{a}}$ \\
Color (L value) & & & \\
Top crust & $53.22 \pm 7.18^{\mathrm{a}}$ & $55.63 \pm 0.82^{\mathrm{a}}$ & $59.69 \pm 10.49^{\mathrm{a}}$ & $62.17 \pm 8.22^{\mathrm{a}}$ \\
Crumb & $74.33 \pm 2.26^{\mathrm{a}}$ & $76.12 \pm 2.43^{\mathrm{a}}$ & $77.13 \pm 0.22^{\mathrm{a}}$ & $75.42 \pm 1.14^{\mathrm{a}}$ \\
\hline
\end{tabular}

${ }^{1)}$ Values represent the mean of four different measurements, ${ }^{2) a-a}$ Same letters in the same row indicate no significant differences between the samples ( $p>0.05$ ) 
Table 5: Comparison of sensory scores between full-fat (control) and reduced-fat muffins containing native and modified (acetylated and hydroxypropylated) rice starches

\begin{tabular}{lccccc}
\hline & Appearance & Grain & Flavor & Texture & Overall acceptability \\
\hline Control & $7.29 \pm 0.76^{\mathrm{a}}$ & $6.71 \pm 0.49^{\mathrm{a}}$ & $6.86 \pm 1.07^{\mathrm{a} 1)}$ & $6.86 \pm 1.21^{\mathrm{a}}$ & $6.86 \pm 0.38^{\mathrm{a}}$ \\
Rice starch & $6.71 \pm 0.95^{\mathrm{a}}$ & $6.00 \pm 1.53^{\mathrm{a}}$ & $5.29 \pm 1.25^{\mathrm{b}}$ & $6.57 \pm 1.51^{\mathrm{a}}$ & $6.00 \pm 1.41^{\mathrm{a}}$ \\
Acetylated RS & $6.71 \pm 0.76^{\mathrm{a}}$ & $6.71 \pm 0.76^{\mathrm{a}}$ & $6.14 \pm 0.90^{\mathrm{ab}}$ & $6.71 \pm 1.98^{\mathrm{a}}$ & $6.71 \pm 0.76^{\mathrm{a}}$ \\
Hydroxypropylated RS & $6.86 \pm 1.07^{\mathrm{a}}$ & $5.86 \pm 0.90^{\mathrm{a}}$ & $6.14 \pm 0.69^{\mathrm{ab}}$ & $7.14 \pm 1.07^{\mathrm{a}}$ & $6.43 \pm 1.13^{\mathrm{a}}$ \\
\hline
\end{tabular}

1)a-bDifferent letters in the same column indicate significant differences between the samples $(p<0.05)$

Table 6: Effect of shortening replacement (at $20 \%$ level) in cookie formulations with native and modified (acetylated and hydroxypropylated) rice starches on the physical characteristics of corresponding baked sugar-snap cookies

\begin{tabular}{lcccc}
\hline Parameter & Control & Rice starch & Acetylated RS & Hydroxypropylated RS \\
\hline Diameter $(\mathrm{cm})$ & $6.77 \pm 0.23^{\mathrm{a} 1)}$ & $6.74 \pm 0.13^{\mathrm{a}}$ & $6.68 \pm 0.21^{\mathrm{a}}$ & $6.68 \pm 0.21^{\mathrm{a}}$ \\
Thickness $(\mathrm{cm})$ & $0.89 \pm 0.01^{\mathrm{b}}$ & $0.96 \pm 0.02^{\mathrm{ab}}$ & $0.91 \pm 0.00^{\mathrm{ab}}$ & $0.98 \pm 0.06^{\mathrm{a}}$ \\
Spread ratio $(\mathrm{D} / \mathrm{T})^{2)}$ & $7.61 \pm 0.30^{\mathrm{a} 4)}$ & $7.02 \pm 0.00^{\mathrm{ab}}$ & $7.34 \pm 0.27^{\mathrm{ab}}$ & $6.82 \pm 0.19^{\mathrm{b}}$ \\
Weight $(\mathrm{g})$ & $20.27 \pm 0.22^{\mathrm{a}}$ & $20.47 \pm 0.99^{\mathrm{a}}$ & $20.31 \pm 0.27^{\mathrm{a}}$ & $20.99 \pm 0.49^{\mathrm{a}}$ \\
Volume (cc) & $34.38 \pm 2.65^{\mathrm{a}}$ & $35.00 \pm 0.60^{\mathrm{a}}$ & $33.75 \pm 1.77^{\mathrm{a}}$ & $36.25 \pm 3.54^{\mathrm{a}}$ \\
Specific gravity $(\mathrm{g} / \mathrm{cc})^{3)}$ & $0.59 \pm 0.02^{\mathrm{a}}$ & $0.58 \pm 0.08^{\mathrm{a}}$ & $0.60 \pm 0.06^{\mathrm{a}}$ & $0.58 \pm 0.03^{\mathrm{a}}$ \\
\hline
\end{tabular}

${ }^{1}$ Values represent the mean of four measurements, ${ }^{2} \mathrm{D} / \mathrm{T}=$ Diameter/thickness of cookies, ${ }^{3}$ Weight/volume of cookies, ${ }^{4)-b}$ Different letters in the same row indicate significant differences between the samples $(p<0.05)$

However, the thickness of cookies was significantly increased with starch addition. Spread ratio decreased, significantly, upon starch addition. A reduction in cookie spread upon the use of fat replacers has been previously reported (Armbrister and Setser, 1994; Sanchez et al., 1995). Whereas, other physical characteristics namely weight, volume and specific gravities of reduced-fat cookies were similar to those of full-fat cookies. However, fat cannot be entirely substituted with starches as fat plays a vital role in low moisture products such as cookies. It is very important for tenderness and mechanical handling (Sanchez et al., 1995). Therefore, in this study, we substituted starches for fat at a level of $20 \%$.

Subjective evaluation shows that the starch substituted cookies, especially native and acetylated rice starches containing ones, exhibited more brightness than the full-fat cookies. However, cookies with hydroxypropylated starch were relatively darker than others.

Regarding sensory characteristics, there were no significant $(p>0.05)$ differences in any of the sensory parameters (top grain, color, flavor and texture) between starches substituted cookies and full-fat cookies. All the observed sensory scores of reduced-fat cookies were more or less the same as those for full-fat cookies. On the 9-point hedonic scale, the average scores of cookies top grain were in the range of 6.57-7.14; color score: 6.71-7.29; flavor: 6.57-7.00; texture: 6.43-6.71; and overall acceptability: 6.29-7.07. The suitability of extruded rice flours as partial substitute of wheat flour for cookie application has been reported earlier (We et al., 2011). Their results indicate that rice flours can be readily substituted for up to $30 \%$ of wheat flour without affecting organoleptic characteristics of cookies. Therefore, rice flour or starch can be used either as partial substitute of wheat flour or shortening (fat) in cookie production.

\section{CONCLUSIONS}

Although rice has been the most important staple food worldwide, rice starch is rarely used as a fat replacer in foods. Recently, our group demonstrated the potentials of native and modified rice starch gels for the formulation of reduced-fat mayonnaise (Puligundla et al., 2015). In the present study, no significant alterations in physical and sensory properties of reduced-fat muffins and reducedfat cookies were noted due to partial substitution of fat by rice starches. From the obtained results, it can be concluded that both native and modified (acetylated and hydroxypropylated) rice starches at substitution levels of $20 \%$ for fat are equally suitable for both reduced-fat muffins and reduced-fat cookies production.

\section{ACKNOWLEDGMENTS}

This work was supported by a grant from IPET, Ministry of Agriculture, Food and Rural Affairs, Republic of Korea.

\section{Author contributions}

Y. L. was involved in designing, conducting the study, and supervised the research project; P.P. was involved in literature collection and manuscript preparation.

\section{REFERENCES}

AACC. 2000. Approved Methods of the AACC. 10th ed. American Association of Cereal Chemists, St. Paul, MN, USA.

Abbas, K. A., S. K. Khalil and A. S. M. Hussin. 2010. Modified 
starches and their usage in selected food products: A review study. J. Agric. Sci. 2: 90-100.

AOAC. 2000. Official Methods of Analysis. 15th ed. Association of Official Analytical Chemists, Washington, DC, USA.

Armbrister, W. L. and C. S. Setser. 1994. Sensory and physical properties of chocolate chip cookies made with vegetable shortening or fat replacers at 50 and $75 \%$ levels. Cereal Chem. 71: 344-351.

Bao, J. and C. J. Bergman. 2001. The functionality of rice starch. In: A. C. Eliasson (Ed.), Starch in Food: Structure, Function and Applications, Woodhead Publishing Limited, Cambridge, Pp. 250-294.

Bello-Perez, L. A., E. Agama-Acevedo, P. B. Zamudio-Flores, G. Mendez-Montealvo and S. L. Rodriguez-Ambriz. 2010. Effect of low and high acetylation degree in the morphological, physicochemical and structural characteristics of barley starch. LWT Food Sci. Technol. 43: 1434-1440.

Choi, S. G. and W. L. Kerr. 2004. Swelling characteristics of native and chemically modified wheat starches as a function of heating temperature and time. Starch-Starke. 56: 181-189.

Chun, S. Y. and B. Yoo. 2007. Effect of molar substitution on rheological properties of hydroxypropylated rice starch pastes. Starch-Starke. 59: 334-341.

Colussi, R., V. Z. Pinto, S. L. M. El Halal, N. L. Vanier, F. A. Villanova, R. M. e Silva, E. da R. Zavareze and A. R. G. Dias. 2014. Structural, morphological, and physicochemical properties of acetylated high, medium, and low-amylose rice starches. Carbohyd. Polym. 103: 405-413.

Gonzalez, Z. and E. Perez. 2002. Effect of acetylation on some properties of rice starch. Starch-Starke. 54: 148-154.

Han, J. A., B. H. Lee, W. J. Lim and S. T. Lim. 2005. Utilization of hydroxypropylated waxy rice and corn starches in Korean waxy rice cake to retard retrogradation. Cereal Chem. 82: 88-92.

Hung, P. V. and N. Morita. 2005. Physicochemical properties of hydroxypropylated and cross-linked starches from A-type and B-type wheat starch granules. Carbohyd. Polym. 59: 239-246.

Jae, H. J., S. B. Jung and J. O. Man. 1994. Physicochemical properties of acetylated rice starches. Korean J. Food Sci. Technol. 25: 123-129.

Kaur, L., N. Singh and J. Singh. 2004. Factors influencing the properties of hydroxypropylated potato starches. Carbohyd. Polym. 55: 211-223.

Lee, I., S. Lee, N. Lee and S. Ko. 2013. Reduced-fat mayonnaise formulated with gelatinized rice starch and xanthan gum. Cereal Chem. 90: 29-34.

Limberger, V. M., F. B. Brum, L. D. Patias, A. P. Daniel, C. G. Comarela, T. Emanuelli and L. P. da Silva. 2011. Modified broken rice starch as fat substitute in sausages. Ciên. Tecnol. Aliment. (Campinas). 31(3): 789-792.

Lin, P. Y., Z. Czuchajowska and Y. Pomeranz. 1994. Enzyme-resistant starch in yellow layer cake. Cereal Chem. 71: 69-75.
Liu, H., H. Ramsden and H. Corke. 1999. Physical properties and enzymatic digestibility of hydroxypropylated $a e, w x$, and normal maize starch. Carbohyd. Polym. 40: 175-182.

Lobato-Calleros, C., C. Ramírez-Santiago, E. J. Vernon-Carter and J. Alvarez-Ramirez. 2014. Impact of native and chemically modified starches addition as fat replacers in the viscoelasticity of reduced-fat stirred yogurt. J. Food Eng. 131: 110-115.

Mirmoghtadaie, L., M. Kadivar and M. Shahedi. 2009. Effects of cross-linking and acetylation on oat starch properties. Food Chem. 116: 709-713.

Phillips, D. L., L. Huijum, P. Duohai and C. Harold. 1999. General application of Raman spectroscopy for the determination of level of acetylation in modified starches. Cereal Chem. 76: 439-443.

Puligundla, P., Y. Cho and Y. Lee. 2015. Physicochemical and sensory properties of reduced-fat mayonnaise formulations prepared with rice starch and starch-gum mixtures. Emirates J. Food Agric. 27: 463-468.

Roller, S. 1996. Starch derived fat mimetics: Maltodextrin. In: Roller, S. and S. A. Jones (Eds.), Handbook of Fat Replacer. CRC Press, New York, Pp. 99-118.

Sanchez, C., C. F. Klopfenstein and C. E. Walker. 1995. Use of carbohydrate-based fat substitutes and emulsifying agents in reduced-fat shortbread cookies. Cereal Chem. 72: 25-29.

Sandrou, D. K. and I. S. Arvanitoyannis. 2000. Low-fat/calorie foods: Current state and perspectives. Crit. Rev. Food Sci. 40: 427-447.

Sodhi, N. S. and N. Singh. 2005. Characteristics of acetylated starches prepared using starches separated from different rice cultivars. J. Food Eng. 70: 117-127.

Stauffer, C. E. 2005. Fats and oils in bakery products. Bailey's Ind. Oil. Fat. Prod. 4: 7.

We, G. J., I. Lee, T. Y. Kang, J. H. Min, W. S. Kang and S. Ko. 2011. Physicochemical properties of extruded rice flours and a wheat flour substitute for cookie application. Food Eng. Prog. 15: 404-412.

Wootton, M. and A. Manatsathit. 1984. The influence of molar substitution on the gelatinization of hydroxypropyl maize starches. Starch-Starke. 36: 207-208.

Wurzburg, O. B. 1964. Acetylation. In: Whistler, R. L., R. J. Smith, J. N. BeMiller, and M. L. Wolfram, Eds.), Methods in Carbohydrate Chemistry, Academic Press, Inc., New York, Pp. 286-288.

Xie, S. X., O. Liu and S. W. Cui. 2005. Starch modification and applications. In: S. W. Cui (Ed.), Food Carbohydrates. Taylor \& Francis Group, Boca Raton, FL, USA, Pp. 357-405.

Yamamoto, K., S. Sumie and O. Toshio. 1973. Properties of rice starch prepared by alkali method with various conditions. Denpun Kagaku. 20: 99-102.

Yeh, A. I. and S. L. Yeh. 1993. Some properties of hydroxypropylated and cross-linked rice starch. Cereal Chem. 70: 596-601.

Yi, C., X. Li, P. Sun and Y. He. 2012. Response surface optimization and characteristics of Indica rice starch-based fat substitute prepared by $\alpha$-amylase. Starch-Starke. 64: 503-509. 